\title{
CLOSED MITRAL VALVOTOMY FOR MITRAL RESTENOSIS: EXPERIENCE IN 113 CONSECUTIVE CASES
}

\author{
R. K. Suri, FAMS, FIACS \\ R. Pathania, MCh \\ N. K. Jha, MCh, DNB \\ H. Singh, MCh \\ R. S. Dhaliwal, MCh, MNAMS \\ S. S. Rana, MCh \\ S. K. Thingnam, $\mathrm{MCh}$ \\ V. Sarwal, MCh \\ J. S. Gujral, FRCS
}

\begin{abstract}
The costs of heart operations and the problems related to anticoagulation after prosthetic valve replacement are among the limitations faced by patients in nonindustrialized countries with mitral stenosis caused by chronic rheumatic heart disease. The young age at which these patients are seen also compels the surgeon to preserve the native valve. The least costly and optimal way to achieve this objective is by closed mitral valvotomy. After closed mitral valvotomy, mitral restenosis is commonly encountered. We report here our 10-year experience with operation on 113 consecutive patients with mitral restenosis. Closed transventricular revalvotomy was performed with Tubbs dilator in 105 of 113 patients. Mean age was 34.3 years, with a male to female ratio of 1:1.5. Most patients were in New York Heart Association functional classes III and IV (74.3\% and $19.4 \%$, respectively). Mean interval between first and second valvotomy was 9.4 years. Hospital mortality rate was $2.8 \%$, trivial postoperative mitral regurgitation occurred in $16.1 \%$, and moderately severe regurgitation occurred in $1.9 \%$. Early postoperative systemic embolism occurred in $3.8 \%$ of the cases. Moderate to excellent symptomatic improvement was noted in $89.4 \%$ of the cases and poor results were seen in $10.2 \%$. Late follow-up of 76 patients ranged from 2 to 10 years (mean 3.8 years), with 39.4\% patients in New York Heart Association class I and 50\% in class II. Close mitral revalvotomy is thus an economical, simple, and safe palliative procedure that carries good long-term results. (J Thorac Cardiovasc Surg 1996;112:727-30)
\end{abstract}

$W^{i}$ ith the introduction of cardiopulmonary bypass, the technique of closed transventricular mitral valvotomy (CMV) for mitral stenosis was virtually abandoned in industrialized countries. This technique continues to be used in most centers in nonindustrialized countries, however, because of its cost-effectiveness and to avoid the problem of anticoagulation therapy after prosthetic mitral valve replacement (MVR). Restenosis is a known complication after CMV, and its prevalence has been reported to range widely, varying between $2 \%$ and

From the Department of Cardiovascular \& Thoracic Surgery, Postgraduate Institute of Medical Education and Research, Chandigarh, India.

Received for publication July 28, 1995; revisions requested Sept. 19, 1995; revisions received Feb. 7, 1996; accepted for publication Feb. 13, 1996.

Address for reprints: R. K. Suri, FAMS, FIACS, Professor and Head, Department of Cardiovascular and Thoracic Surgery, Postgraduate Institute of Medical Education and Research, Sector 12, Chandigarh-160 012, India.

Copyright (C) 1996 by Mosby-Year Book, Inc.

0022-5223/96\$5.00+0 12/1/72659
$60 \% .^{1-3}$ Approximately $10 \%$ of patients returning to the hospital with persistent or recurrent symptoms 6 years after operation have true restenosis, ${ }^{4}$ Virtually no differences have been reported with respect to the short-term results achieved with the three available palliative procedures: CMV, open mitral valvotomy or commissurotomy (OMV), and balloon mitral valvotomy (BMV). ${ }^{5}$ It will take more time, however, for evaluation of long-term results of OMV and BMV.

Considering the relatively younger age at which our patients are seen and their socioeconomic status, our effort has been to adopt a palliative procedure with a low cost and without problems of anticoagulation, while at the same time preserving the native valve. In this retrospective study, we analyzed the results of CMV in 105 of total 113 consecutive patients with mitral restenosis at the Post Graduate Institute of Medical Education and Research, Chandigarh, India.

\section{Patients and methods}

This study comprises 113 consecutive patients with mitral restenosis who underwent reoperation during a 
Table I. Patient age at CMR $(n=113)$

\begin{tabular}{lrc}
$\begin{array}{c}\text { Age group } \\
(y r)\end{array}$ & No. & $\%$ \\
\hline $13-25$ & 13 & 11.5 \\
$26-40$ & 71 & 62.8 \\
$41-50$ & 24 & 21.2 \\
$>50$ & 05 & 4.4 \\
TOTAL & 113 & - \\
\hline
\end{tabular}

Table II. Preoperative echocardiographic findings $(n=113)$

\begin{tabular}{lrr}
\hline \multicolumn{1}{c}{ Pathology } & No. & $\%$ \\
\hline Calcification & 43 & 38.0 \\
Mild & 24 & 21.2 \\
Moderate & 13 & 11.5 \\
Severe & 6 & 5.3 \\
Subvalvular pathology & 78 & 68.9 \\
Mild & 46 & 40.7 \\
Moderate & 28 & 24.7 \\
Severe & 4 & 3.5 \\
Left atrial clot & 2 & 1.7 \\
\hline
\end{tabular}

Mean valve area $0.74 \mathrm{~cm}^{2}$.

10-year period (January 1982 to December 1992). These patients were evaluated clinically and echocardiographically. Most were found to be suitable candidates for closed mitral revalvotomy (CMR). Six patients with heavily calcified valves underwent MVR, and two patients in whom a left atrial clot was detected on echocardiography underwent OMV. In the remaining 105 patients, CMR was carried out. One hundred two of these patients underwent CMR for the first time and three patients had successful second CMRs. Patients who had symptoms within 3 years of the first CMV were excluded from this study because they were considered to have an inadequate initial valvotomy.

Of 113 patients with mitral restenosis, 45 were male and 68 were female (1:1.5). Their ages ranged from 14 to 56 years, with a mean of 34.3 years (Table I). Most of the patients were in New York Heart Association functional classes III (74.3\%) and IV (19.4\%). Hemoptysis was present in $15.9 \%$ of the patients, and atrial fibrillation was present in $55 \%$ of the patients. Preoperative systemic embolic episodes occurred in 11 patients $(10 \%)$, with detectable left atrial clot in only two. The mean interval between first CMV and CMR was 9.4 years; that between first CMV and MVR was 6.2 years. Preoperative echocardiographic findings are listed in Table II. Mean mitral valve area according to echocardiography was $0.74 \mathrm{~cm}^{2}$.

A left anterolateral thoracotomy approach was used for all patients. Through the previous incision scar, the chest was entered through the bed of the fifth rib. Adhesions were separated by sharp dissection to expose the body of the left atrium, adjacent left superior pulmonary vein, and left ventricular apex. Double purse-string sutures of 2-0 Prolene (Ethicon, Inc., Somerville, N.J.) or silk were placed over the body of left atrium, extending onto the
Table III. Operative complication of CMR (105

\begin{tabular}{crr} 
cases) & & \\
\hline Complication & No. & $\%$ \\
\hline Mitral regurgitation & 19 & 18.0 \\
Trivial & 17 & 16.1 \\
Severe & 2 & 1.9 \\
Systemic embolism & 4 & 3.8 \\
Intraoperative hypotension & 12 & 11.4 \\
Intraoperative ventricular & 3 & 2.8 \\
$\quad$ fibrillation & & \\
Failure to dilate valve & 1 & 0.9 \\
\hline
\end{tabular}

entry of left superior pulmonary vein, for introduction of the surgeon's right index finger. Another mattress suture with 2-0 silk was placed at the left ventricular apex adjacent to the previous ventriculotomy site for introduction of a Tubbs dilator. The orifice of the mitral valve was dilated to 3.25 or $3.5 \mathrm{~cm}$ in diameter.

A total of 76 patients who had undergone CMR were evaluated clinically and with echocardiography. Evaluation was performed 2 to 10 years (mean 3.8 years) after operation.

\section{Results}

A complete and satisfactory commissurotomy was achieved in 95 of the 105 patients who underwent CMR. In one case, the procedure had to be abandoned because the Tubbs dilator could not be negotiated across the mitral valve orifice as a result of severe subvalvular pathology. Postcommissurotomy mitral regurgitation occurred in 19 patients. Regurgitation was trivial in 17 patients $(16.1 \%)$ and moderately severe in two patients $(1.9 \%)$. Of the two patients with moderately severe mitral regurgitation, one underwent emergency MVR and the other died before operation of acute intractable pulmonary edema and low cardiac output. Postoperative systemic embolism occurred in four patients (3.8\%). Intraoperative ventricular fibrillation that could be successfully converted with direct current shock occurred in three patients. Operative complications are listed in Table III. Early in-hospital death (defined as death occurring within 30 days after operation) after CMR was $2.8 \%$. There were no operative complications in the three patients who underwent a second CMR. Causes of death after CMR for mitral restenosis are shown in Table IV.

Echocardiography from 84 patients at first follow-up ( 1 to 3 months) showed adequate valvotomy (mitral valve area $\geq 1.75 \mathrm{~cm}^{2}$ ) in $88.1 \%$ and inadequate valvotomy (mitral valve area $<1.75 \mathrm{~cm}^{2}$ ) in $11.9 \%$. Mean mitral valve area was $1.82 \mathrm{~cm}^{2}$. The functional statuses of 76 patients at 2- to 10-year 
Table IV. Cause of death after CMR $(n=105)$

\begin{tabular}{lc}
\hline \multicolumn{1}{c}{ Cause } & No. \\
\hline Cerebral embolism & 1 \\
Low cardiac output with mitral & 1 \\
$\quad$ regurgitation & \\
Ventricular arrhythmia & 1 \\
Total deaths & 3 \\
\hline
\end{tabular}

follow-up (mean 3.8 years) are shown in Table V. The occurrences of restenosis were 8.4 at 5 years and 20.2 at 10 years per 1000 patients per year after CMR. None of our patients had any evidence of recurrence of acute rheumatic activity. There was no subsequent increase in mitral regurgitation among patients in whom trivial mitral regurgitation perioperative had developed.

\section{Discussion}

CMV is an established surgical procedure for treatment of mitral restenosis, however, only a few studies assessing its results have been reported. ${ }^{1,6,7}$ The current consensus in industrialized countries favors open operative techniques. ${ }^{2,8}$ Despite many reports on the effectiveness of OMV, it is not certain whether the results are sufficiently superior to those of CMV to justify the higher cost involved in an open procedure, an important factor particularly in nonindustrialized countries. ${ }^{9}$ Farhat and associates ${ }^{10}$ reported a mean mitral valve area of $2.1 \mathrm{~cm}^{2}$ after OMV for noncalcific mitral stenosis. In earlier reports, survival after CMV was rather disappointing. ${ }^{11,12}$ Recent studies, however, have shown low early and late mortality rates after CMV both for primary mitral stenosis and restenosis. ${ }^{1,6,13}$ MVR carries the risk of thromboembolism, mechanical failure, prosthetic valve endocarditis, and problems related to anticoagulation. The incidences of mitral regurgitation after CMV and OMV are similar. The reported incidence of MVR after OMV in a follow-up of 4.4 years to 8.6 years is $7 \%$ to $18 \%$. $^{2,14}$ Younger surgeons have shown a preference for MVR. ${ }^{15,16}$

Although BMV has recently gained popularity, ${ }^{10,17-20}$ its cost and short-term palliative results compared with those achieved by CMV are limiting factors. ${ }^{21}$ In the available literature, there are no reports defining the role of percutaneous BMV for mitral restenosis. ${ }^{22}$ The results of surgical commissurotomy (OMV, CMV) and BMV are similar, ${ }^{14,23,24}$ and only the patient's preference and the cost factor guide the choice of the procedure to be
Table V. Functional status at late follow-up (2 to $10 \mathrm{yr}$, mean $3.8 \mathrm{yr} ; n=76$ )

\begin{tabular}{cccccc}
\hline \multirow{2}{*}{$\begin{array}{c}\text { NYHA Functional } \\
\text { Class }\end{array}$} & \multicolumn{2}{c}{ Preoperative } & & \multicolumn{2}{c}{ Postoperative } \\
& No. & $\%$ & & No. & $\%$ \\
\hline I & 0 & 0 & 30 & 39.4 \\
II & 4 & 5.2 & & 38 & 50 \\
III & 62 & 81.5 & & 7.6 \\
IV & 10 & 13.1 & & 2 \\
\hline
\end{tabular}

NYHA, New York Heart Association.

performed. In an editorial, Frater ${ }^{5}$ cautioned that the results achieved by BMV are as good as those of CMV, provided that complications (including residual atrial septal defect, cardiac perforation, and iatrogenic mitral regurgitation) are not in excess of those associated with operation. It has been predicted that in appropriately selected patients the long-term clinical outcome after BMV may be expected to be similar to the available data for surgical commissurotomy (OMV, CMV). ${ }^{25}$

Restenosis is the result not only of inadequate valvotomy but also of a continuing fibrotic process. ${ }^{1}$ Progressive restenosis correlates not only with time but also with the pathologic state of valve at surgical intervention. ${ }^{5}$ The relatively younger age of our patients, a mean of 34.3 years, forced us to evolve a strategy to conserve the native valve through CMV or CMR. Any other procedure would have led to increased costs and lesser acceptability of a valvular prosthesis in our social milieu. Logically, the basic social circumstances and inadequate health care facilities available for our population group at risk, compels us to adopt the most cost-effective procedures in our country. The results have been so gratifying in our patients that we believe every effort should be made to preserve the native valve until a more acceptable valve substitute is available.

MVR caries the hazards of anticoagulation, with the necessity of life-long expenditure and strict treatment compliance. Because most of our population at risk has a rural background and poor socioeconomic status, compliance with an anticoagulation schedule is always doubtful in our country, and noncompliance often leads to serious postMVR complications.

In our experience, the early operative mortality rate is less than that reported for earlier series, ${ }^{6,13}$ is easily comparable with that of $\mathrm{OMV},{ }^{8,26,27}$ and is certainly less than that for MVR. ${ }^{28}$ Mitral regurgitation carries an important prognostic significance for functional outcome necessitating $\mathrm{MVR}^{19,20}$ but 
was trivial in most of our cases $(16.1 \%)$. There is no reported difference in the prevalences of mitral regurgitation associated with the three palliative procedures available for the treatment of mitral stenosis. ${ }^{25}$ The limitation common to CMV, BMV, and $\mathrm{OMV}$ is calcified valve; that common to both CMV and BMV is left atrial clot.

\section{Conclusion}

New York Heart Association functional class improved in most of our patients after CMR. In our opinion, CMV for mitral restenosis still offers excellent palliation with low risk, low cost, and good long-term results in most patients, without the hazards of anticoagulation.

\section{REFERENCES}

1. John S, Bashi VV, Jairaj PS, Muralidharan S, Ravikumar E, Rajarajeswari $T$, et al. Closed mitral valvotomy: early results and long-term follow-up of 3724 consecutive patients. Circulation 1983;68:891-6.

2. Arora R, Khalilullah M, Gupta MP, Padmavati S. Mitral restenosis: incidence and epidemiology. Indian Heart J 1978; 30:265-9.

3. Heger JJ, Wann LS, Weyman AE, Dillon JC, Feigenbaum $\mathbf{H}$. Long-term changes in mitral valve area after successful, mitral commissurotomy. Circulation 1979;59:443-8.

4. Higgs LM, Glancy DL, O'Brien KP, Epstein SE, Morrow AG. Mitral restenosis: an uncommon cause of recurrent symptoms following mitral commissurotomy. Am J Cardiol 1970;26:34-7.

5. Frater RW. Balloon vs surgical commissurotomy [editorial]. J Heart Valve Dis 1995;4:444-5.

6. John S, Perianayagam WJ, Abraham KA, Jairaj PS, Krishnaswami S, Sukumar IP, et al. Restenosis of the mitral valve: surgical consideration and results of operation. Ann Thorac Surg 1978;25:316-21.

7. Mullin EM Jr, Glancy DL, Higgs LM, Epstein SE, Morrow AG. Current results of operation for mitral stenosis: clinical and hemodynamic assessments in 124 consecutive patients treated by closed commissurotomy, open commissurotomy, or valve replacement. Circulation 1972;46:298-308.

8. Nakano S, Kawashima Y, Hirose H, Matsuda H, Shirakura $\mathrm{R}$, Sato $\mathrm{S}$, et al. Reconsiderations of indications for open mitral commissurotomy based on pathologic features of the stenosed mitral valve. J Thorac Cardiovasc Surg 1987;94:33642.

9. Jacovella G, Vajola FS, Masini V, et al. Reinterventi su commissurotomia-indicazioni e resultati: nostra esperienza su 39 casi. Minerva Cardioangiol 1974;22:691-6.

10. Farhat MB, Boussadia H, Gandjbakhch I, Mzali H, Chouaieb A, Ayari M, et al. Closed versus open mitral commissurotomy in pure noncalcific mitral stenosis: hemodynamic studies before and after operation. J Thorac Cardiovasc Surg 1990; 99:639-44.

11. Ellis LB, Benson H, Harken DE. The effect of age and other factors on the early and late results following closed mitral valvuloplasty. Am Heart J 1968;75:743-51.
12. Gross RI, Cunningham JN Jr, Snively SL, Catinella FP, Nathan IM, Adams PX, et al. Long-term results of open radical mitral commissurotomy: ten year follow-up study of 202 patients. Am J Cardiol 1981;47:821-5.

13. Salerno TA, Neilson IR, Charrette EJ, Lynn RB. A 25-year experience with the closed method of treatment in 139 patients with mitral stenosis. Ann Thorac Surg 1981;31:300-4.

14. Essop MR. Relief of rheumatic mitral stenosis: when and how? Am J Cardiol 1994;73:85-7.

15. Roberts WC, Lachman AS. Mitral valve commissurotomy versus replacement: considerations based on examination of operatively excised stenotic mitral valves. Am Heart J 1979; 98:56-62.

16. Laschinger JC, Cunningham JN Jr, Baumann FG, Isom OW, Catinella FP, Mendelsohn A, et al. Early open radical commissurotomy: surgical treatment of choice for mitral stenosis. Ann Thorac Surg 1982;34:287-98.

17. Inoue $\mathbf{K}$, Owaki T, Nakamura T, Kitamura F, Miyamoto N. Clinical application of transvenous mitral commissurotomy by a new balloon catheter. J Thorac Cardiovasc Surg 1984; 87:394-402.

18. Lock JE, Khalilullah M, Shrivastava S, Bahi V, Keane JF. Percutaneous catheter commissurotomy in rheumatic mitral stenosis. N Engl J Med 1985;313:1515-8.

19. Hickey MS, Blackstone EH, Kirklin JW, Dean LS. Outcome probabilities and life history after surgical mitral commissurotomy: implications for balloon commissurotomy. J Am Coll Cardiol 1991;17:29-42.

20. Wilkins GT, Weyman AG, Abascal VM, Block PC, Palacios I. Percutaneous mitral valvotomy: an analysis of echocardiographic variables related to outcome and the mechanism of dilatation. Br Heart J 1988;60:299-308.

21. Rothlisberger C, Essop MR, Skudicky D, Skoularigis J, Wisenbaugh T, Sareli P. Results of percutaneous balloon mitral valvotomy in young adults. Am J Cardiol 1993;72: 73-7.

22. Block PC, Tuzeu EM, Palacious I. Percutaneous mitral balloon valvotomy. Cardiol Clin 1991;9:271-87.

23. Patel JJ, Sharma D, Mitha AS, Blyth D, Hassen F, Le Roux BT, et al. Balloon valvuloplasty versus closed commissurotomy for pliable mitral stenosis: a prospective hemodynamic study. J Am Coll Cardiol 1991;18:1318-22.

24. National Heart, Lung and Blood Institute, Balloon Valvuloplasty Registry. Multicenter experience with balloon mitral commissurotomy: the NHLBI balloon valvuloplasty registry report on immediate and 30 day follow up results. Circulation 1992;84:448-61.

25. Essop R, Rothlisberger C, Dullabh A, Sareli P. Can the long term outcome of percutaneous balloon mitral valvotomy and surgical commissurotomy be expected to be similar? J Heart Valve Dis $1995 ; 4: 446-52$.

26. Peper WA, Lytle BW, Cosgrove DM, Goormastic M, Loop FD. Repeat mitral commissurotomy: long term results. Circulation 1987;76:(Suppl 3)97-101.

27. Yun KL, Miller DC. Mitral valve repair versus replacement. Cardiol Clin 1991;9:315-27.

28. Rutledge R, McIntosh CL, Morrow AG, Picken CA, Siwek LG, Zwischenberger JB, et al. Mitral valve replacement after closed mitral commissurotomy. Circulation 1982;66(2 Pt 2): I162-6. 